\title{
Evolution of Smart Healthcare: Telemedicine During COVID-19 Pandemic
}

\author{
Geetanjali Sageena $^{1} \cdot$ Munish Sharma ${ }^{2}$ Ajita Kapur ${ }^{3}$
}

Received: 3 July 2020/Accepted: 26 February 2021 / Published online: 3 April 2021

(C) The Institution of Engineers (India) 2021

\begin{abstract}
Telemedicine is considered as the "Natural evolution of healthcare in the digital world." In India, considering the vast geographical spread, predominant rural population, and sound medicinal services overwhelmingly accessible in urban areas, telemedicine has immense potential to grow from its nascent stages. The progression of technology-enabled transformations will provide an impetus to reshape the contours of India's healthcare. Epidemics and pandemics pose a monumental challenge for healthcare professionals. To mitigate the impacts, extending telemedicine's emergence and utilization can serve as one of the most effective approaches to broaden our perspectives. Further proactive intervention and exploration to increase comprehension of how telemedicine could be applied during pestilence circumstances needs to be expedited. The prospects for smart healthcare are vast; thus, embracing the recent advancement of information and communication technology can lead to indelible healthcare management changes. The present review outlines the status, challenges, and need to promote telemedicine's rapid progression in India, especially during the pandemic emergency rooms.
\end{abstract}

Keywords Telemedicine $\cdot$ Epidemic .

COVID-19 pandemic $\cdot$ Healthcare management

Geetanjali Sageena

geetanjali.sageena@keshav.du.ac.in

1 Department of Environmental Studies, Keshav Mahavidyalaya, University of Delhi, New Delhi, India

2 Department of General Surgery, Kalpana Chawla Govt. Medical College, Karnal, Haryana, India

3 Kalpana Chawla Govt. Medical College, Karnal, Haryana, India

\section{Introduction}

Telemedicine is the roadmap for substantial healthcare arising from the effective fusion of information and communication technology (ICT) with Medical Science. In a developing nation like India with a sundry population of more than 135 crores, there is substantial inequitable distribution of healthcare services. In addition, a large share $(\sim 68.84 \%)$ of the population of Indians resides in rural areas (with minimal healthcare services), whereas $75 \%$ of doctors are based on cities [1].

The woeful doctor-patient ratio, i.e., one doctor for 1,000 people in India, needs to be addressed at par with WHO recommendation [2]. The data propose that India has one specialist for every 1445 people [2]. According to the World Health Organization (WHO), India positions 184th out of 191 nations regarding the level of GDP spent on medicinal services. While India's healthcare is one of the fastest-growing markets globally, it has been slow to adopt technology-driven initiatives [3]. Access to clinical consideration is an ethical human right, and it turns into a commitment to provide health services to all individuals, even in remote and rustic zones where services might be inaccessible.

A few years back, telemedicine was viewed as cutting edge and experimental. However, today it is presently developing as a revolutionary tool for convenient and specialized healthcare, especially for patients in remote areas with limited access to standardized healthcare services. To understand the winning leap vision, India needs to view its various economic and social challenges as open doors for renewal and development. Technology is set to have an unprecedented impact on healthcare in building the foundation blocks towards a holistic healthcare ecosystem. The idea of virtual healthcare has been around before the 
world was struck by the pandemic posing an utter challenge to India's traditional healthcare system. Amid this situation, telemedicine is emerging as a viable option to improve efficiency, enhance resilience, and anticipate risks. Even the government emphasizes the use of ICT to bring an ocean of progress in the medicine sector.

\section{History of Telemedicine}

The term telemedicine was coined in the 1970s [4]."Tele" is a Greek word signifying "distance, "and "mederi" is a Latin word signifying "to heal." American Telemedicine Association (ATA) has defined telemedicine as "The natural evolution of healthcare in the digital world." The allure of telehealth is in using electronic information to communicate technologies to provide and support healthcare over a distance [5]. According to WHO, Telemedicine is the delivery of healthcare services, where distance is a critical factor, by all healthcare professionals using information and communication technologies for the exchange of valid information for diagnosis, treatment, and prevention of disease and injuries, research and evaluation, and for the continuing education of healthcare providers, all in the interests of advancing the health of individuals and their communities" [6]. Telemedicine has an assortment of applications in understanding patient care, public health, education, and research [7].

Historically, telemedicine can be followed back to the mid to late nineteenth century [8] with the first published record in the mid-twentieth century when electrocardiograph (ECG) information was transmitted over phone wires [9]. The Radio News magazine (April 1924 issue) brought telemedicine's earliest endeavors with a new dream for future public health. The cover indicated a patient with a $\mathrm{TV}$ and receiver to speak with a doctor at the opposite end [10].

In 1959 at the University of Nebraska, the specialists utilized the first known interactive telemedicine video consultation to transmit neurological examinations [11]. During telemedicine's early development, NASA (National Aeronautics and Space Administration) played a crucial role. To provide healthcare services to space explorers, NASA (1972-1975) brought about Space Technology Applied to Rural Papago Advanced Health Care (STARPAHC), which delivered clinical care to the Papago Indian Reservation in Arizona [12]. NASA also utilized satellite innovation in telemedicine and found its profound role in disaster management during the earthquake at the Mexico City and Soviet Armenia earthquake in 1985 and 1988, respectively [13]. Using Telemedicine, NASA laid the foundation of the commercial space center, MITAC (Medical Informatics and Technology Applications Consortium) at Yale University (1997), paving the way for the current trend of private participation in public health management [12].

\section{Telemedicine in India}

In contrast to the bleak situation in medicinal services, ICT proficiency is seen to proliferate in undeserved regions of industrialized countries and developing nations [14]. The activities related to telemedicine started in 1999 in India, though the Government of India (GoI) made the first move to introduce telemedicine in the nation in the year 2000 . The Indian Space Research Organization deployed the first SATCOM (satellite communication) based Telemedicine Pilot Project in 2001 at Andhra Pradesh [15]. Initiatives taken by ISRO, Ministry of Health and Family Welfare, Ministry of External Affairs, Department of Information Technology (DIT), and the state governments assumed a crucial job in advancing telemedicine administrations in India.

Various projects like National Rural Telemedicine Network, National Cancer Network (ONCONET), Integrated Disease Surveillance Project (IDSP), National Medical College Network, and the Digital Medical Library Network are taken up by the Ministry of Health in the Government of India, aiming to coalesce public health data to provide easy access[16]. Setting up of telemedicine practice guidelines by the Government of India and setting up of a National Telemedicine Task Force by the Health Ministry in 2005 were a portion of the other positive strides. Worldwide activities like the SAARC (South Asian Association for Regional Co-activity) Telemedicine Network Project and the Pan-African e-Network Projects have likewise been taken up as an activity of the External Affairs Ministry [17]. Despite having so much potential, telemedicine has not achieved the 'blast' that it was intended to make due to a lack of awareness and acceptance of new technology. Telemedicine is essentially an effective and versatile product of the twenty-first century. Some anticipate that telemedicine will significantly change the healthcare service delivery in the industrialized world by migrating away from clinics and hospitals into homes [18]. Through successful joint efforts of government and private healthcare institutions, telemedicine could be a giant leap in healthcare and help bridge the gap between rural-urban India, strategically placing Indian telemedicine in the global scenario.

For quite a long while, the range and practicality of telehealth were limited. At present, Apollo Telehealth runs around 700 healthcare centers in Public-Private partnership mode across India and significantly spread across various states, touching more than 11.4 million lives. In the recent decades, as the utilization of wireless broadband has developed, and cell phones and web use have become 
ubiquitous, patient training with pictures and recordings, transfer of clinical pictures like X-rays, Ultrasound, and video conferencing turned into a reality[19]. Improvement in internet infrastructure for information transmission, encryption, password protection, HIPAA (Health Insurance Portability and Accountability Act of 1996) guidelines [20], digitalizing data, and establishment of EMRs (electronic clinical records) made e-healthcare and telemedicine cost-effective [19]. Venturing into the twenty-first century, different national/international associations like the American Telemedicine Association, Washington DC, have been set up - which are exclusively dedicated to telemedicine services [21].

The present-day telemedicine with no special training utilizes existing processing gadgets like cell phones, cameras, wearable biosensors for clinical information, which made it simpler to use. In rural India, a bunch of healthtech start-ups are now endeavoring to build up a useful telemedicine framework. Practo (https://www.practo. com/health-app) - one of the primary success permits patients to talk with experienced specialists on the web. Urban India has the upside of players like rxtelemed ( http://rxtelemed.com/), mfine (https://www.mfine.co/), DocsApp (https://www.docsapp.in/), and Lybrate (https://www.lybrate.com/) at the patients-specialists interface for smooth access and sharing of clinical information. Start-ups such as Meddo (www.meddo.in) and Navia Lifecare (https://www.navialifecare.com/) have also implemented teleconsultations via voice and video facilities. There is Kollam-based Waferchips Techno Solutions ( http://waferchips.co.in/), which created Biocalculus, an ambulatory heart checking gadget that functions as a wearable electrocardiography (ECG) device.

Vadodara-based healthtech start-up "I Online Doctor" ( https://ionlinedoctor.com/) intends to tap the telemarket by associating patients with specialists through secure video calls utilizing a portable application, having more than 2,000 specialists and more than 45 healthcare professionals on board. MedCords (https://www.medcords.com/) received Rs 15 lakh funding from the Rajasthan Government's start-up activity iStart in October 2018 ( https://istart.rajasthan.gov.in/events). As the segment develops, Apollo Healthcare plans to touch the lives of 30 million individuals by 2022 by effectively partnering with governments and other healthcare providers for the expansion of telehealth benefits [22]. The ongoing telemedicine practices for a common man lessen travel costs, spares time, decrease clinical expenses and provide simpler healthcare specialists access.

\section{Role of Telemedicine in COVID-19 Pandemic}

The flare-up of Novel Coronavirus Disease (COVID-19) barely needs any prelude; it has brought the entire world to a standstill. History is repeating itself, and humanity is facing a novel viral pandemic. The clarion call evoked thoughts for handling the widespread disaster. The plausible worst-case scenario of COVID-19 represents the extent of deaths and a significant global economic contraction. Nonetheless, the learning from the past's wreckages reaffirms that the human species is resilient to such catastrophic events [23]. The primary challenge is how to contain the contamination to spread and provide adequate healthcare to the infected individuals.

Numerous nations, including India, have secured physical distancing as a measure to contain the spread of the infection to countless individuals. The lockdown has helped to delay the spread of the infection and plan clinical healthcare facilities to cope with the emergent situation. In any case, given the populace size and inadequate infrastructure, physical distancing might be hard to remain enforced upon the rollback of lockdown.

According to a study at Shiv Nadar University, India could have witnessed a surge of 31,000 cases of disease between 24 March and 14 April without lockdown.[24].

With the resumption of easing limitations on individuals and transport development, the surge in COVID-19 positive cases increasingly poses a threat. The anxieties about the fast spread of coronavirus pandemic in country districts with many transients returning to their towns are likewise genuine. India has proceeded onward to the open stage even as a spurt of COVID -19 positive cases keep on observing a spike in the nation's critical industrialized and urbanized pockets. However, there exists no room for complacency. Also, lockdown has brought an enormous loss of livelihood. Thus, it poses a big challenge for a nation like India to guarantee well-being security without compromising the citizens' livelihood security.

In the era of global increasing competition and rapid change, innovation holds the key to success. There is no denying that the whole healthcare fraternity is battling against contagion relentlessly. The most advanced and mighty countries are racing against the time to mitigate the exploits of COVID-19. In the pursuit of truce, we must galvanize to reset and rethink. In the wake of the COVID19 outbreak, fast progression in innovation will assist, accomplishing the objectives of providing readily accessible, cost-effective, and quality health services to all. Telemedicine can be a necessary break from the sloppiness of patient records. Simultaneously, it can diminish transportation costs the patient needs to manage and overcome any barrier of correspondence that numerous rural healthcare centers face in an emergency. As a part of our 
commitment to the nation and welfare of society, we perceive our job unitedly battling this pandemic and achieving this goal! Modern technology should be at the heart of stimulus plans to deal with a pandemic situation. Telemedicine can act as a frontline weapon will go far in keeping not only coronavirus at bay but also as a service provider to trauma patients suffering from other acute/ chronic diseases.

The five fundamental types of telemedicine are classified (Fig. 1) based on the duration of information transmitted or according to the interaction of individuals involved [25].

As per the timings of the information transmitted.

1. Real-time or Synchronous Telemedicine (where the sender and recipient both are online at a similar purpose of time and live information gets transferred).

2. Store-and-Forward or Asynchronous Telemedicine (where the sender stores the information and sends it to the recipient as per convenience, and the beneficiary can survey the information indicated by his/her comfort).

3. Self- Testing or Remote Monitoring (where technological gadgets are utilized to screen the well-being and clinical indications of a patient remotely)

As per the interaction between the people in question:

1. Health expert to Patient (giving medicinal services to the unreached populace by giving them direct access to a clinical expert).

2. Health Expert to Health Expert (giving simpler access to claim to consultation services, referral, and specialty care).

To strengthen the "Make in India" initiative in the health sector, we must use information technology-related tools to create healthier societies and popularize "new models" of telemedicine. By 2025, the telemedicine market in India is expected to reach $\$ 5.4$ billion [26]. The Ayushman Bharat Scheme by the Indian government is empowering telemedicine for the advancement of the health sectors in the nation.

On 25 March 2020, NITI Aayog released the new Telemedicine Practice Guidelines empowering Registered Medical Practitioners (RMPs) to provide healthcare services remotely according to Telemedicine guidelines. At the outset of COVID-19, it has become evident that: (i) The essential foundation for network is broadly accessible, most promptly through the smartphone. (ii) Outpatient visits can be clinically managed from a distance, i.e., patients with non-emergency can be triaged to telemedicine administration without trading off their well-being. (iii) The government relaxed all prohibitive telemedicine guidelines, reimbursement, interstate permits, and most significantly, information confidentiality issues. (iv) The necessary logistics can be developed promptly and shall offer no resistance to the protective modality.

Telemedicine is rising as a promising tool for better clinical care to patients at home, saving time, providing cost-effective, and prompt access to healthcare services. Simultaneously, health professionals can see numerous patients, thus increasing revenue, e-data analysis increasing practice efficiency, providing better diagnosis, informed decision, and management. Telemedicine is a bright spot in the future of healthcare. As per a report distributed by the Global Market Insights in March 2019, the telemedicine market was esteemed at over $\$ 38.3$ billion in 2018 and is expected to develop more than 19 percent CAGR between 2019 and 2025. The early adoption of a regulatory framework will help in rapid growth. Undoubtedly, it is short-sighted to consider telemedicine's utility as constrained to taking care of the current emergency whose utility will disseminate when the pandemic emergency at galloping pace is over. Although the unfolding occasions have demonstrated the value of our vision for broadening the scope of health assets, for those in need, irrespective of distance and time boundaries explicitly through telemedicine, it is likewise an opportunity to keep up the guardrails for efficient clinical care. Clinicians must observe prevailing standards, and the quality of care in telemedicine must not be compromised in any way or no lesser than in-person care, including prompt reporting of adverse events, proper documentation, and follow-up. Simultaneously, correct inferences should be made regarding the lessons gained from our experience extensively by the telemedicine community, healthcare professionals, policymakers, and society. We must step forward towards expansion in technological opportunities to accelerate the growth and development of the nation. However, there can be certain associated challenges in telemedicine implementation, such as lack of awareness, good infrastructure (particularly in rural India), language barrier, ignorance, and lack of guidelines.

With an aim to provide preventive and curative healthcare services to the patients in rural areas, especially those belonging to the bottom of the economic pyramid, the Uttar Pradesh Government has decided to implement telemedicine services in its various Primary Health Centers (PHCs) and Community Health Centers (CHCs). The project, proposed to be developed on a public private partnership (PPP) model, provides establishment, deployment, operation, and maintenance services. The project has two components: teleconsultation and video consultation. It has been rolled out to connect patients with specialists using technology rather than transferring the specialists to remote locations to treat the patients. Healthcare centers which require telemedicine services have been identified, 


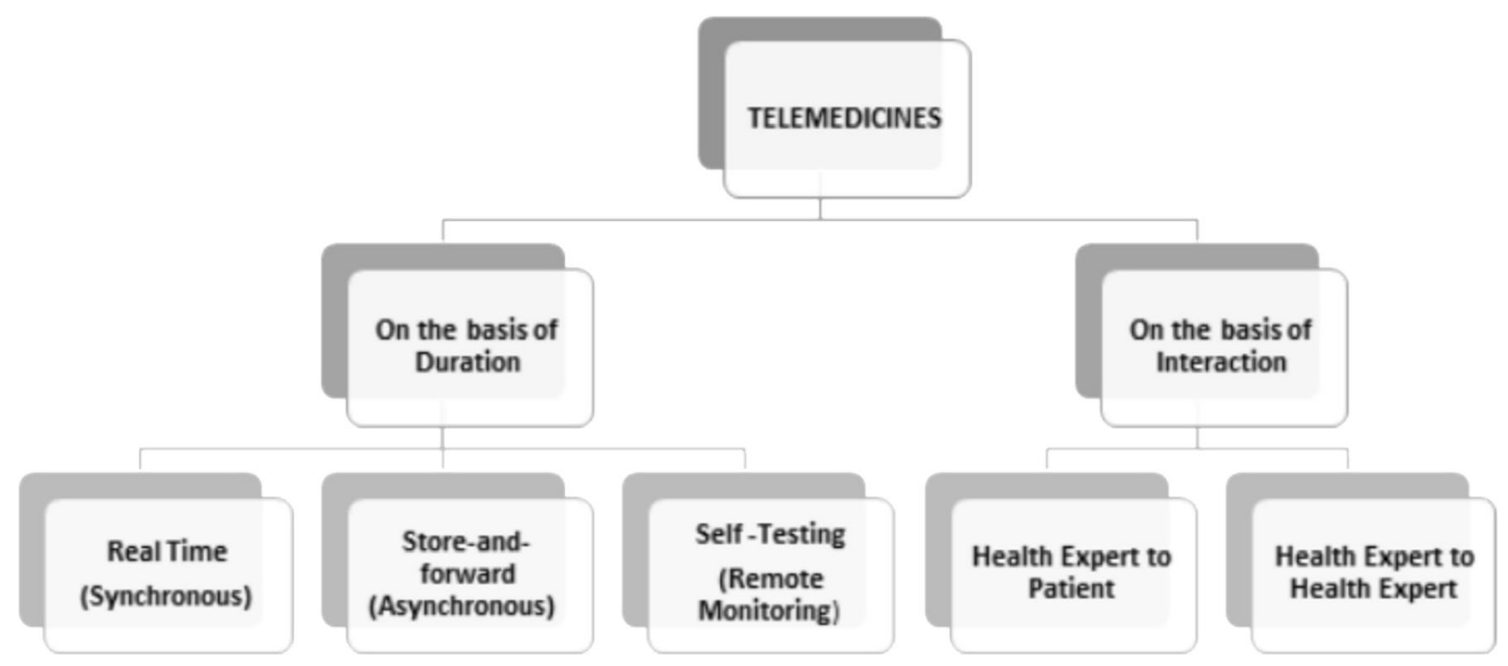

Fig. 1 Types of telemedicine

and a framework has been developed for the involvement of the private sector. A set up of a 50-seater call center has also been proposed for teleconsultations.

The government assigned MBBS doctor would facilitate the video consultation with the specialist, when required. Thereafter, if the specialist identifies the need for patients to visit the hospital, the patient will be referred to the relevant facility. However, in other cases, required medical assistance maybe provided at the center without the patient traveling to far off hospitals. This makes it a cost—efficient model for service delivery for both the users as well as the service providers [27].

\section{Conclusion}

Specifically, in the Indian scenario of low doctor to patient ratio, telemedicine can be a new frontier to navigate from COVID-19 pandemic mode to "new normal." Perhaps, this could be a slide back to conventional medical healthcare facilities. The healthcare burden on the country is gigantic, and online consultation platforms can fulfill the healthcare needs. The Telemedicine adoption will reduce the cost of the nation's healthcare system. Clinical professionals can screen many patients and thus lessen the specialists' burden, performing remote counsels when required. Nonemergency patients can be easily treated and monitored online, thus saving time. While telemedicine will have farreaching advantages, it will offer much-needed access to healthcare services in rural areas. Telemedicine become a critical asset, minimizing the direct human to human exposure, with fewer chances to get contaminated, reducing the risk of coronavirus transmission amidst pandemic. At present, telemedicine is an approach to overcome the shortage of numerous essential goods and services, from masks and hand sanitizers to tele-ICU. As a country and an economy, India is currently on a level-playing field with the developed nations. It is appropriate that policymakers need to evolve a new framework that embraces a holistic approach to all stakeholders and needs to underscore more on the execution of measures. The judicious mix must integrate innovation and policy at the best convergence to enable agile and technologically advanced innovation deals in the strategic sector. The genuine danger of COVID-19 expands well beyond the current time frame. The situation would be the change of COVID-19 from a one-time pandemic occasion into an endemic, coursing for all time inside the human populace. This initiative would anchor and kick-start, creating an innovation ecosystem in the field of medicine.

Compliance with ethical standards

Conflict of interest All authors declare no conflict of interest.

\section{References}

1. Censusindia.gov.in, CENSUS OF INDIA. [online] GOI. [cited 2018 Dec 2] (2012). http://censusindia.gov.in/2011-prov-results/ paper2/data_files/india/Rural_Urban_2011.pdf

2. Density of physicians [Internet], World Health Organization. [cited 2018 Dec 03]. https://www.who.int/gho/health_workforce/ physicians_density/en/

3. W. Einthoven, Dates back to the telecardiogram. Arch. Int. Physiol. 4, 132-164 (1905)

4. E.M. Strehle, N. Shabde, One hundred years of telemedicine: does this new technology have a place in paediatrics? Arch. Dis. Childh. 91(12), 956-959 ( 2006)

5. A. Allen, D. Allen, Telemedicine programs: 2nd annual review reveals doubling of programs in a year. Telemed. Today $\mathbf{3}(1)$, 10-14 (1995)

6. Telemedicine-Opportunities and developments in member states [Internet] 2nd ed. Geneva, Switzerland: WHO Press, 2010. [cited 
2019 Feb 1]. https://www.who.int/goe/publications/goe_teleme dicine_2010.pdf

7. K. Ganapathy, Neurosurgeon, Apollo Hospitals, Chennai, Telemedicine in India-the Apollo experience, Neurosurgery on the Web (2001)

8. J. Craig, V. Patterson, Introductiontothepracticeoftelemedicine. J. Telemed. Telecare 11(1), 3-9 (2005)

9. E.W. Le, Le télécardiogramme [The telecardiogram]. Arch. Int. Physiol. 4, 132-164 (1906)

10. Radio news, April 1942 [Internet]. Americanradiohistory.com. [cited 2018 Dec 01]. https://www.americanradiohistory.com/Arc hive-Radio-News/20s/Radio-News-1924-04-R.pdf .

11. J. Marilyn, Telemedicine: A Guide to Assessing Telecommunications in Health Care (National Academy, Field, Washington, D.C., 1996).

12. N. Brown, A brief history of telemedicine. Telemed. Inf. Exchange. 105, 833-835 (1995)

13. A Brief History of NASA's Contributions to Telemedicine [Internet]. NASA. [cited 2018 Dec 01]. https://www.nasa.gov/con tent/a-brief-history-of-nasa-s-contributions-to-telemedicine/

14. R. Wootton, L.S. Jebamani, S.A. Dow, E-health and the Universitas 21 organization: 2. Telemedicine and underserved populations. J. Telemed. Telecare 11(5), 221-224 (2005)

15. ISRO Telemedicine Initiative [Internet]. Televital.com.[cited 2019 Feb 1]. http://www.televital.com/downloads/ISRO-Teleme dicine-Initiative.pdf .

16. S. Mishra, L. Kapoor, I. Singh, Telemedicine in India: Current scenario and the future. E Health. 15, 568-575 (2009)
17. Ministry of External Affairs, Government of India [Internet]. Mea.gov.in. [cited 2018 Dec 01]. http://www.mea.gov.in/

18. P.J. Heinzelmann, N.E. Lugn, J.C. Kvedar, Telemedicine in the future. J. Telemed. Telecare 11(8), 384-390 (2005)

19. History of Telemedicine-md Portal [Internet]. md Portal.2015. [cited 2018 Dec 02]. http://mdportal.com/education/history-of-t elemedicine

20. Health Information Privacy [Internet]. HHS.gov. [cited 201901 January]. https://www.hhs.gov/hipaa/index.html .

21. Home-ATA Main [Internet]. Americantelemed.org. [cited 2019 Feb 01]. http://www.americantelemed.org/home

22. https://www.expresshealthcare.in/interviews/apol lo-telehealth-will-upgrade-100-primary-healthcare-deliverycentres-of-the-government-in-collaboration-with-a-local-partnerin-malaysia/418075/

23. J. Littman, M.L. Littman, Galen and the Antonine Plague R. Am. J. Philol. 94(3), 243-255 (1973)

24. Sagar Kulkarni, India would have seen 31,000 coronavirus cases without lockdown: researches. Deccan Herald. Retrieved 4 April 2020 (3 April 2020).

25. V.G. Chellaiyan, A.Y. Nirupama, N. Taneja, Telemedicine in India: Where do we stand? J Family Med Prim Care 8(6), 1872-1876 (2019)

26. EY-Parthenon's Life after COVID-19 Survey, 2020.

27. EY study: EY FICCI 2.0 Reengineering Indian Healthcare report.

Publisher's Note Springer Nature remains neutral with regard to jurisdictional claims in published maps and institutional affiliations. 